\title{
Cholangiocellular Carcinoma
}

\author{
Arndt Vogel Anna Saborowski \\ Department of Gastroenterology, Hepatology and Endocrinology, Hannover Medical School, Hannover, Germany
}

\section{Keywords}

Cholangiocarcinoma · Biliary tract cancer · Chemotherapy ·

Targeted therapy

\begin{abstract}
Background: Cholangiocarcinomas (CCAs) are aggressive malignancies that display features of biliary differentiation. According to their anatomical location, CCAs are commonly classified as intrahepatic and extrahepatic tumors, the latter entity being further subdivided into perihilar CCAs, also termed as Klatskin tumors, and distal tumors. While a majority of CCAs occur sporadically, established risk factors such as liver fluke infestation or primary sclerosing cholangitis exist. Summary: Due to lack of efficient early screening markers, CCAs are frequently diagnosed at an advanced stage when curative surgical resection is not an option. Chemotherapy with gemcitabine and cisplatin is currently the standard palliative treatment that prolongs overall survival by 3.6 months as compared to monotherapy with gemcitabine. For CCA patients who progress under gemcitabine/cisplatin, the paucity of prospective, randomized trials is detrimental, and there is currently no recommended second-line regimen with respect to chemotherapy or loco-regional treatment modalities. Molecular profiling of CCAs supports the implementation of targeted approaches, and it is reasonable that personalized therapy will become a mainstay of CCA treatment. In addition, the advent of immunotherapy holds
\end{abstract}

considerable promise, yet, similar to targeted treatment, needs to be prospectively evaluated in clinically and genetically thoroughly characterized patients. Key Points: (1) CCA is a genetically diverse and highly aggressive malignancy. (2) Gemcitabine in combination with cisplatin or oxaliplatin is the current first-line chemotherapy in non-resectable patients. (3) Loco-regional treatment modalities exist but need to be evaluated in prospective randomized trials in the context of systemic chemotherapy. (4) Targeted therapies in molecularly defined subgroups of patients and immunotherapies alone or in combinations will most likely improve survival in the future.

(c) 2017 S. Karger AG, Basel

\section{Epidemiology and Risk Factors}

Cholangiocarcinomas (CCAs) are rare tumors, with an overall incidence ofless than $2 / 100,000$ [1]. The epidemiological profiles of CCA subtypes vary significantly, reflecting the exposure to different risk factors and most likely different genetic backgrounds. CCA incidence ranges between 0.1/100,000 in Australia and more than 130/100,000 in parts of Asia [2]. Epidemiological studies looking at the prevalence in different countries and regions have mostly but not uniformly reported a rise in CCA [3-6]. In Germany, mortality of intrahepatic CCA (IH-CCA) has more than tripled between 1998 and 2008. In line with the

\section{KARGER}

(c) 2017 S. Karger AG, Basel

E-Mail karger@karger.com

www.karger.com/dig 
increased mortality data, the number of reported cases of IH-CCA also increased between 1970 and 2006 [7].

A vast majority of CCAs (70\%) occur sporadically without any apparent cause. However, several risk factors that promote cholangiocarcinogenesis have been identified. In East Asia, infestation with the liver flukes Opisthorchis viverrini and Clonorchis sinensis by ingestion of raw or pickled fish is a major risk factor [8]. In Western populations, the strongest association has been established for primary sclerosing cholangitis (PSC), with or without accompanying inflammatory bowel disease [9]. Cholangiocarcinogenesis has also been associated with different forms of cholelithiasis and rare congenital anomalies of the bile duct such as Caroli's disease $[10,11]$. More recently, hepatitis $B$ and hepatitis $C$ virus infection and infection-associated cirrhosis as well as diabetes and obesity have been shown to increase the risk for CCA development [10,12-14]. Notably, most of the designated risk factors are associated with recurrent cholangitis and chronic local inflammation, indicating that inflammation acts as an underlying pathogenic mechanism in cholangiocarcinogenesis.

\section{Prevention and Surveillance}

Preventive measures are relevant in endemic regions and include health education (routes of parasitic and viral infection), vaccination, and antiviral therapies, as well as avoiding exposure to toxins such as 1,2-dichloropropane. Preclinical studies have shown that COX-2 is implicated in early cholangiocarcinogenesis [15]. Accordingly, regular aspirin intake was associated with a reduced incidence and mortality in various cancer types within observational studies [16]. Specifically, a 2.7- to 3.6-fold decreased risk for CCA was reported in a casecontrol study, encouraging prospective trials investigating the potential benefit of aspirin in selected risk groups [17].

Surveillance, including imaging and testing of liver enzymes and tumor markers, has been suggested as a suitable method for early cancer detection in high-risk groups, such as patients with PSC. However, recommendations concerning the modality and frequency of screening are inconsistent, and implementation of stratified surveillance standards tailored to the distinct risk groups is warranted $[1,18]$. In the absence of established biomarkers, screening efforts in the near future will most likely rely on imaging modalities, specifically ultrasound, and in selected high-risk groups on MRI.

\section{Pathogenesis}

The molecular landscape of CCA is highly heterogeneous, and the genetic profiles segregate with the anatomical location, the histological subtype, as well as with the putative pathogenic risk factors. It is increasingly recognized that CCA is not a uniform disease with respect to the cancer cell of origin, and that indeed different liverresident cells as well as cells lining the biliary tree have the propensity to give rise to specific subclasses of CCA. The heterogeneity of tumor-initiating cells may account for the genetic profiles that diverge across the anatomical and morphological features.

Despite the genetic diversity, a recurrent repertoire of driver genes and potentially targetable lesions exists: indeed, across 239 biliary tract cancers (including 28 gallbladder cancers), $40 \%$ of patients harbored targetable lesions [19], indicating targeted therapy will complement therapeutic approaches, yet only in highly stratified patient groups. Key molecular pathways involved in cholangiocarcinogenesis comprise activated RAS- and PI3K signaling, deregulated NOTCH signaling, and loss of Tp53-guided cell cycle control. In addition, the high frequency of inactivating mutations in chromatin remodeling genes (ARID1a, PBRM1, BAP1) as well as recurrent mutations in IDH1 and 2 points towards a crucial role of epigenetic regulation in cholangiocarcinogenesis. Recently, gene fusion events, frequently involving a portion of the tyrosine kinase receptor FGFR2, were identified especially in IH-CCA and represent potential therapeutic targets [20].

A hallmark feature of CCA is the prominent desmoplastic stroma. While our current understanding of the role of the tumor microenvironment is limited, the tumor stroma likely contributes to tumor initiation, progression, and treatment response. A better understanding of the complex crosstalk between tumor cells and stroma cells will be crucial to address the therapeutic promises and perils associated with targeting the tumor stroma.

\section{Surgery and Adjuvant Therapy}

Radical resection is the treatment of choice but is feasible only in $25-35 \%$ of all patients [21]. Locally advanced or metastatic disease due to late diagnosis precludes curative surgery in the majority of patients, and high recurrence rates even after resection further aggravate the dismal prognosis: in a cohort of 175 extrahepatic CCA patients, the 5-year overall survival (OS) rate following curative resection was $26 \%$ [22]. A retrospective analysis 
of $221 \mathrm{IH}$-CCA patients surgically resected in our clinic yielded a 3 -year OS rate of 40 vs. $36.4 \%$ after R0 and R1 resection respectively [23].

Liver transplantation is no standard therapy for CCA patients but might be a promising option for cure in highly select patients. A recent retrospective study including patients who were first diagnosed with IH-CCA at explant pathology after liver transplantation reported a 5 -year recurrence rate of $18 \%$ in patients with single tumors $\leq 2 \mathrm{~cm}$, compared to $61 \%$ in patients with tumors $>2 \mathrm{~cm}$ or multifocal disease [24].

Considering the high risk of relapse following surgery, the potential benefit of adjuvant therapies needs to be explored. In a recent meta-analysis of published data, adjuvant chemotherapy appears to be associated with a survival benefit in patients with lymph node-positive disease and adjuvant chemoradiotherapy in patients with microscopically involved margins (R1 resection) [25]. Currently, 3 ongoing phase III trials address the potential benefit of adjuvant treatment following curative resection: the BilCap study in England (comparing capecitabine versus observation) and the PRODIGE-12 study in France (comparing gemcitabine and oxaliplatin versus observation) have completed recruitment and are awaiting data maturation. In Germany, the ACTICCA study comparing gemcitabine and cisplatin versus observation is still recruiting.

\section{Local Therapies}

Subclinical or frank cholangitis is associated with increased morbidity and mortality. Efficient endoscopic or percutaneous biliary drainage is not only crucial to enhance prognosis and quality of life but is frequently also a prerequisite for palliative therapy. Local tumor ablation through photodynamic therapy was introduced as a treatment modality in 1991 and improved survival in small clinical trials and retrospective studies compared to best supportive care. Moreover, for patients presenting with liver-confined disease, additional loco-regional therapies are available, including intraductal percutaneous radiofrequency ablation, high-dose-rate brachytherapy, as well as transarterial approaches, such as hepatic arterial infusion chemotherapy, transarterial chemoembolisation, $90 Y$ ttrium radioembolisation, and external beam radiation, but most of these treatment modalities were evaluated retrospectively or as single-center studies [26]. The only prospective study, the French FFCD 9902 phase III trial comparing chemoradiotherapy with $5-\mathrm{FU}$ and cisplatin to gemcitabine and oxaliplatin in patients with locally advanced CCA, was discontinued early because a trend for prolonged survival in the chemotherapy alone arm was observed [27]. Prospective evaluation is clearly required to assess the impact of local therapies on the morbidity and mortality of patients with CCA, specifically in the context of systemic chemotherapy.

\section{Systemic Therapies}

CCA is an intrinsically highly chemoresistant malignancy. However, most patients with CCA are eventually bound to receive non-curative treatment. In 2010, the randomized phase III ABC-02 study compared gemcitabine as a single agent to a combination chemotherapy with gemcitabine and cisplatin in 410 patients with locally advanced or metastatic CCA, GBC, or ampullary carcinoma. The median survival was significantly prolonged by 3.6 months in the group that received gemcitabine in combination with cisplatin than with gemcitabine alone, with no overt increase in toxicity [28]. Similar results were observed in a Japanese randomized phase II trial and confirmed in a pooled analysis of both trials [29]. Therefore, the combination of gemcitabine and cisplatin is nowadays the standard first-line treatment for non-resectable CCA. When contraindications, such as renal insufficiency, exist, cisplatin may be replaced by oxaliplatin $[30,31]$. Singleagent treatment with gemcitabine is still considered appropriate for elderly or moribund patients. In addition to gemcitabine-based chemotherapy, fluoropyrimidines have shown efficacy in the treatment of CCA [32] and patients with tumor progression under firstline chemotherapy frequently receive a fluoropyrimidine based second-line regime. However, a recent metaanalysis of 14 non-randomized phase II trials concluded that there is insufficient evidence to recommend second-line chemotherapy [33]. To assess whether patients may benefit from second-line mFOLFOX regime compared to best supportive care, the randomized first phase III study ABC06 Trial (NCT01926236) is currently recruiting.

\section{Targeted Therapies}

The field of oncology has changed in the last years by the introduction of targeted therapies. Indeed, targeted approaches have revolutionized the treatment of several 
tumor entities, such as leukemia, non-small cell lung cancer or melanoma. In CCA, however, the overall success of targeted strategies has been rather modest so far.

Initial promising results from nonrandomized phase II studies triggered a significant interest in targeting the epithelial growth factor receptor. The early enthusiasm, however, was dampened by the recently published phase II study BINGO that concluded that there was no benefit of intensifying gemcitabine and oxaliplatin by the addition of cetuximab [34]. Moreover, the German PICCA study evaluating the efficacy of panitumumab in combination with gemcitabine and cisplatin in KRAS wildtype patients was also negative for the primary endpoint PFS with no improvement of OS. Finally, results from a phase III trial evaluating gemcitabin and oxaliplatin with or without erlotinib in patients with CCA, GBC, or ampullary cancer were similarly disappointing [35].

Proteins of the vascular endothelial growth factor (VEGF) family are well recognized as mediators of angiogenesis and vascular permeability but may have additional pro-tumorigenic effects on immune cells and tumor cells themselves. Studies investigating the VEGF-A antibody bevacizumab, the VEGF inhibitor cediranib and the multikinase inhibitor sorafenib failed to show convincing anti-tumoral activity in CCA both as a single agent as well as in combination therapy [36-38]. Currently, ramucirumab, a VEGFR2-directed monoclonal antibody, is evaluated in a phase-II study in combination with gemcitabine and cisplatin.

\section{Future Directions}

The median survival for patients with metastatic CCA with current chemotherapy options is still less than 1 year, highlighting the urgent need to develop more effective systemic treatments. Recent sequencing efforts have shed light on the mutational landscape of CCA, and new molecular classifications provide the groundwork for novel therapeutic options for advanced CCA. Particularly, the discovery of IDH mutations and FGFR2 fusions in IH-CCA is of significance as pharmacologic inhibitors have been developed and first studies investigating their anti-tumor efficacy have been initiated in CCA. Finally, several biomarker studies on biliary tract tumor samples have shown a high rate of PD-L1 expression in these tumors, providing a rationale to consider immunotherapy. First clinical trials are ongoing and response rates of $20 \%$ were reported in selected PDL-1 positive advanced patients with pembrolizumab [39]. Moreover, promising data exist for microsatellite-instability - high CCAs which have a high rate of somatic mutation - with respect to progression-free survival in response to checkpoint inhibition [40].

\section{Disclosure Statement}

A.V. served as a consultant, received speakers honoraria, and/ or travel expenses from Amgen, Bayer, Baxalta/Shire, BMS, MSD, Lilly, and Roche.

\section{References}

1 Bergquist A, von Seth E: Epidemiology of cholangiocarcinoma. Best Pract Res Clin Gastroenterol 2015;29:221-232.

2 Sripa B, Pairojkul C: Cholangiocarcinoma: lessons from Thailand. Curr Opin Gastroenterol 2008;24:349-356.

3 Khan SA, Taylor-Robinson SD, Toledano MB, Beck A, Elliott P, Thomas HC: Changing international trends in mortality rates for liver, biliary and pancreatic tumours. J Hepatol 2002;37:806-813.

4 Patel T: Increasing incidence and mortality of primary intrahepatic cholangiocarcinoma in the United States. Hepatology 2001;33:13531357.

5 Mosadeghi S, Liu B, Bhuket T, Wong RJ: Sexspecific and race/ethnicity-specific disparities in cholangiocarcinoma incidence and prevalence in the USA: an updated analysis of the 2000-2011 Surveillance, Epidemiology and
End Results registry. Hepatol Res 2016;46: 669-677.

6 Saha SK, Zhu AX, Fuchs CS, Brooks GA: Forty-year trends in cholangiocarcinoma incidence in the U.S.: intrahepatic disease on the rise. Oncologist 2016;21:594599.

7 von Hahn T, Ciesek S, Wegener G, Plentz RR, Weismuller TJ, Wedemeyer H, Manns MP, Greten TF, Malek NP: Epidemiological trends in incidence and mortality of hepatobiliary cancers in Germany. Scand J Gastroenterol 2011;46:1092-1098.

8 Watanapa P, Watanapa WB: Liver fluke-associated cholangiocarcinoma. Br J Surg 2002;89: 962-970.

9 Ehlken H, Schramm C: Primary sclerosing cholangitis and cholangiocarcinoma: pathogenesis and modes of diagnostics. Dig Dis 2013;31:118-125.
10 Shaib YH, El-Serag HB, Davila JA, Morgan R, McGlynn KA: Risk factors of intrahepatic cholangiocarcinoma in the United States: a case-control study. Gastroenterology 2005; 128:620-626.

11 Abdalla EK, Forsmark CE, Lauwers GY, Vauthey JN: Monolobar Caroli's disease and cholangiocarcinoma. HPB Surg 1999;11:271-276; discussion 276-277.

12 Ralphs S, Khan SA: The role of the hepatitis viruses in cholangiocarcinoma. J Viral Hepat 2013;20:297-305.

13 Tyson GL, El-Serag HB: Risk factors for cholangiocarcinoma. Hepatology 2011;54:173-184.

14 Welzel TM, Graubard BI, El-Serag HB, Shaib YH, Hsing AW, Davila JA, McGlynn KA: Risk factors for intrahepatic and extrahepatic cholangiocarcinoma in the United States: a population-based case-control study. Clin Gastroenterol Hepatol 2007;5:1221-1228. 
15 Boonmasawai S, Akarasereenont P, Techatraisak K, Thaworn A, Chotewuttakorn S, Palo T: Effects of selective COX-inhibitors and classical NSAIDs on endothelial cell proliferation and migration induced by human cholangiocarcinoma cell culture. J Med Assoc Thai 2009;92:1508-1515.

16 Elwood PC, Morgan G, Pickering JE, Galante J, Weightman AL, Morris D, Kelson M, Dolwani S: Aspirin in the treatment of cancer: reductions in metastatic spread and in mortality: a systematic review and meta-analyses of published studies. PLoS One 2016;11: e0152402.

17 Choi J, Ghoz HM, Peeraphatdit T, Baichoo E, Addissie BD, Harmsen WS, Therneau TM, Olson JE, Chaiteerakij R, Roberts LR: Aspirin use and the risk of cholangiocarcinoma. Hepatology 2016;64:785-796.

18 Plentz RR, Malek NP: Clinical presentation, risk factors and staging systems of cholangiocarcinoma. Best Pract Res Clin Gastroenterol 2015;29:245-252.

19 Nakamura H, Arai Y, Totoki Y, Shirota T, Elzawahry A, Kato M, Hama N, Hosoda F, Urushidate T, Ohashi S, Hiraoka N, Ojima H, Shimada K, Okusaka T, Kosuge T, Miyagawa S, Shibata T: Genomic spectra of biliary tract cancer. Nat Genet 2015;47:1003-1010.

20 Sia D, Losic B, Moeini A, Cabellos L, Hao K, Revill K, Bonal D, Miltiadous O, Zhang Z, Hoshida Y, Cornella H, Castillo-Martin M, Pinyol R, Kasai Y, Roayaie S, Thung SN, Fuster J, Schwartz ME, Waxman S, Cordon-Cardo C, Schadt E, Mazzaferro V, Llovet JM: Massive parallel sequencing uncovers actionable FGFR2-PPHLN1 fusion and ARAF mutations in intrahepatic cholangiocarcinoma. Nat Commun 2015;6:6087.

21 Neumann UP, Schmeding M: Role of surgery in cholangiocarcinoma: from resection to transplantation. Best Pract Res Clin Gastroenterol 2015;29:295-308.

22 van der Gaag NA, Kloek JJ, de Bakker JK, Musters B, Geskus RB, Busch OR, Bosma A, Gouma DJ, van Gulik TM: Survival analysis and prognostic nomogram for patients undergoing resection of extrahepatic cholangiocarcinoma. Ann Oncol 2012;23:2642-2649.

23 Bektas H, Yeyrek C, Kleine M, Vondran FW, Timrott K, Schweitzer N, Vogel A, Jager MD, Schrem H, Klempnauer J, Kousoulas L: Surgical treatment for intrahepatic cholangiocarcinoma in Europe: a single center experience. J Hepatobiliary Pancreat Sci 2015;22: 131-137.

24 Sapisochin G, Facciuto M, Rubbia-Brandt L, Marti J, Mehta N, Yao FY, Vibert E, Cherqui D, Grant DR, Hernandez-Alejandro R, Dale $\mathrm{CH}$, Cucchetti A, Pinna A, Hwang S, Lee SG, Agopian VG, Busuttil RW, Rizvi S, Heimbach JK, Montenovo M, Reyes J, Cesaretti M, Soubrane O, Reichman T, Seal J, Kim PT, Klint- malm G, Sposito C, Mazzaferro V, Dutkowski P, Clavien PA, Toso C, Majno P, Kneteman N, Saunders C, Bruix J; iCCA International Consortium: Liver transplantation for "very early" intrahepatic cholangiocarcinoma: International retrospective study supporting a prospective assessment. Hepatology 2016;64: 1178-1188.

25 Horgan AM, Amir E, Walter T, Knox JJ: Adjuvant therapy in the treatment of biliary tract cancer: a systematic review and meta-analysis. J Clin Oncol 2012;30:1934-1940.

26 Vogel A, Dudeck O: Is there any evidence for a role of local treatment in cholangiocarcinoma? Viszeralmedizin 2014;30:254-260.

27 Phelip JM, Vendrely V, Rostain F, Subtil F, Jouve JL, Gasmi M, Michel P, Le Malicot K, Smith D, Seitz JF, Fauchart JP, Martin P, Bennouna J, Morin T, Bonnet I, Maingon P, Lepage $\mathrm{C}$, Chauffert $\mathrm{B}$ : Gemcitabine plus cisplatin versus chemoradiotherapy in locally advanced biliary tract cancer: fédération Francophone de Cancérologie Digestive 9902 phase II randomised study. Eur J Cancer 2014;50:2975-2982.

28 Valle J, Wasan H, Palmer DH, Cunningham D, Anthoney A, Maraveyas A, Madhusudan $S$, Iveson T, Hughes S, Pereira SP, Roughton $\mathrm{M}$, Bridgewater J; ABC-02 Trial Investigators: Cisplatin plus gemcitabine versus gemcitabine for biliary tract cancer. N Engl J Med 2010;362:1273-1281.

29 Okusaka T, Nakachi K, Fukutomi A, Mizuno N, Ohkawa S, Funakoshi A, Nagino M, Kondo S, Nagaoka S, Funai J, Koshiji M, Nambu Y, Furuse J, Miyazaki M, Nimura Y: Gemcitabine alone or in combination with cisplatin in patients with biliary tract cancer: a comparative multicentre study in Japan. Br J Cancer 2010;103:469-474.

30 Andre T, Reyes-Vidal JM, Fartoux L, Ross P, Leslie M, Rosmorduc O, Clemens MR, Louvet C, Perez N, Mehmud F, Scheithauer W: Gemcitabine and oxaliplatin in advanced biliary tract carcinoma: a phase II study. Br J Cancer 2008;99:862-867.

31 Jang JS, Lim HY, Hwang IG, Song HS, Yoo N, Yoon S, Kim YH, Park E, Byun JH, Lee MA, Oh SJ, Lee KH, Kim BS, Oh SC, Kim SY, Lee SJ: Gemcitabine and oxaliplatin in patients with unresectable biliary cancer including gall bladder cancer: a Korean Cancer Study Group phase II trial. Cancer Chemother Pharmacol 2010;65:641-647.

32 Romiti A, D'Antonio C, Zullo A, Sarcina I, Di Rocco R, Barucca V, Durante V, Marchetti P: Chemotherapy for the biliary tract cancers: moving toward improved survival time. J Gastrointest Cancer 2012;43:396-404.

33 Lamarca A, Hubner RA, David Ryder W, Valle JW: Second-line chemotherapy in advanced biliary cancer: a systematic review. Ann Oncol 2014;25:2328-2338.
34 Malka D, Cervera P, Foulon S, Trarbach T, de la Fouchardiere C, Boucher E, Fartoux L, Faivre S, Blanc JF, Viret F, Assenat E, Seufferlein T, Herrmann T, Grenier J, Hammel P, Dollinger M, Andre T, Hahn P, Heinemann V, Rousseau V, Ducreux M, Pignon JP, Wendum D, Rosmorduc O, Greten TF; BINGO Investigators: Gemcitabine and oxaliplatin with or without cetuximab in advanced biliary-tract cancer (BINGO): a randomised, open-label, non-comparative phase 2 trial. Lancet Oncol 2014;15:819-828.

35 Lee J, Park SH, Chang HM, Kim JS, Choi HJ, Lee MA, Jang JS, Jeung HC, Kang JH, Lee HW, Shin DB, Kang HJ, Sun JM, Park JO, Park YS, Kang WK, Lim HY: Gemcitabine and oxaliplatin with or without erlotinib in advanced biliary-tract cancer: a multicentre, open-label, randomised, phase 3 study. Lancet Oncol 2012;13:181-188.

36 Moehler M, Maderer A, Schimanski C, Kanzler S, Denzer U, Kolligs FT, Ebert MP, Distelrath A, Geissler M, Trojan J, Schutz M, Berie L, Sauvigny C, Lammert F, Lohse A, Dollinger MM, Lindig U, Duerr EM, Lubomierski N, Zimmermann S, Wachtlin D, Kaiser AK, Schadmand-Fischer S, Galle PR, Woerns M; Working Group of Internal Oncology: Gemcitabine plus sorafenib versus gemcitabine alone in advanced biliary tract cancer: a double-blind placebo-controlled multicentre phase II AIO study with biomarker and serum programme. Eur J Cancer 2014;50:31253135.

37 Bengala C, Bertolini F, Malavasi N, Boni C, Aitini E, Dealis C, Zironi S, Depenni R, Fontana A, Del Giovane C, Luppi G, Conte P: Sorafenib in patients with advanced biliary tract carcinoma: a phase II trial. Br J Cancer 2010;102:68-72.

38 El-Khoueiry AB, Rankin CJ, Ben-Josef E, Lenz HJ, Gold PJ, Hamilton RD, Govindarajan R, Eng C, Blanke CD: SWOG 0514: a phase II study of sorafenib in patients with unresectable or metastatic gallbladder carcinoma and cholangiocarcinoma. Invest $\mathrm{New}$ Drugs 2012;30:1646-1651.

39 Bang YJ, Doi T, De Braud F, Piha-Paul S, Hollebecque A, Razak ARA, Lin CC, Ott PA, He AR, Yuan SS, Koshiji M, Lam B, Aggarwal R: Safety and efficacy of pembrolizumab (MK-3475) in patients (pts) with advanced biliary tract cancer: Interim results of KEYNOTE-028. European Journal of Cancer 2015;51:S112-S112.

40 Le DT, Uram JN, Wang H, Kemberling H, Eyring A, Bartlett B, Goldberg RM, Crocenzi TS, Fisher GA, Lee JJ, Greten TF, Laheru D, Azad NS, Donehower RC, Luber B, Koshiji M, Eshleman JR, Anders RA, Vogelstein B, Diaz LA: PD-1 blockade in mismatch repair deficient non-colorectal gastrointestinal cancers. J Clin Oncol 2016;34(suppl 4S):abstr 195. 